\title{
Creative writing and Critical Thinking Enhancement at Higher Education
}

\section{Antonella Poce, Francesca Amenduni}

Department of Educational Sciences, University of Roma Tre, Italy.

\begin{abstract}
Currently, educational policy makers identify Critical Thinking (CT) as an essential driver for development and knowledge growth in any field and in the broad society. Peer interactions and writing activities are helpful pedagogical strategies for CT enhancement especially when supported by the use of technologies (Guiller, Durndell, \& Ross, 2008).

Starting from the above-mentioned evidence, a university module was designed by combining collaborative and creative writing sessions based on critical analysis of literary texts and the fruition of figurative arts. 123 students worked in groups and their CT level was assessed at different times of the course. Most of the students' groups showed an increase of their CT level. The difficulties in the management of group dynamics corresponded to CT level decreasing. On the contrary, groups able to organize their work improved their CT throughout the course. Additionally, students' work modes had an impact on their performance at different CT tasks. The research results could be used to improve university course design for CT education.
\end{abstract}

Keywords: Creative writing; Critical thinking; Collaborative learning. 


\section{Introduction and state of the art}

Educational policy makers identify Critical Thinking (CT) as an essential driver for progress and knowledge growth in any field and in the broad society. However, CT is still a disputed concept with several different definitions that come from many approaches. CT is commonly defined as "purposeful, self-regulatory judgment that results in interpretation, analysis, evaluation, and inference, as well as explanations of the considerations on which that judgment is based" according to the definition produced in the Delphi Report (Facione, 1990) that is partially affected by the philosophical tradition related to CT definition. Although those perspectives on CT refer to an individual working on his own on a problem based task, recent perspectives suggest that CT may evolve thanks to the important role it could play in various types of information exchange or symbolic interaction (Byrnes \& Dunbar, 2014). Much of our knowledge of the world comes from others, rather than being the result of primary experience, and requires an analysis and critical evaluation of sources, internal coherence and relation to other sources of information. Also Kuhn (1991) emphasizes the social element in his definition of CT as a type of reasoned argument. The social element in Kuhn refers to the articulation and discussion of ideas with peers who are engaged in a collaborative process of knowledge building. Language skills are important precursors for all high-level thought processes. By regulating thoughts through internal speech and navigating social situations through external speech, language help people process information at increasingly sophisticated levels over time, providing foundation to be engaged in CT. According to Graff (2008), being engaged in a dialogic argument provides the "missing interlocutor" that gives a purpose to the written argument. Peer interactions also provide an opportunity to gain experience or practice in CT, specifically through understanding others' perspectives and creating and fulfilling joint goals (Murphy, Rowe, Ramani \& Silverman, 2014). Recent studies have highlighted how technology could be implemented in collaborative learning settings in order to enhance CT (Schindler, \& Burkholder 2014). One potential advantage of computer-mediated discussion is its asynchronous nature, allowing more time for reflection before responding. An increase in the use of formal, evidence-based reasoning and the quality of CT can be due to an extension of the time available to think and consult sources of information. In a well-known study of Newman Webb, and Cochrane (1995) they found similar level of students' CT in the online and face-to-face discussion whereas other authors show (Guiller, Durndell, \& Ross, 2008) evidence of increased CT level in the online situation, especially in terms of justification. Not only dialogical and collaborative activities seem to affect positively CT, but also other forms of communication, such as individual writing. Quitadamo and Kurtz (2007) compared CT level of students who participated in a laboratory writing treatment with those who experienced traditional quiz-based laboratory in a general education biology course. They found that, unlike the nonwriting group, writing group significantly improved 
CT skills, in particular, analysis and inference skills. Kuhn and Crowell (2011) suggested to combine dialogical activities with the use of the individual essay in order to assess the transfer of skills from the social to the individual level. Also Ennis (1993) suggests the adoption of short essay items for assessment purposes because it would capture more effectively the disposition aspect of CT compared to what multiple-choice items formats would do. However, in a 2004 study (Condon, \& Kelly-Riley, 2004) it was found that the better the writing, the lower the CT score. According to the authors, the lack of relationship between writing and CT scores indicates that having students write does not automatically mean that we ask students to think critically. They assert that writing acts as a vehicle for CT, but writing is not itself CT. For example, if writing tasks call for summary and fact reporting, there is no reason to suspect that students' performances will incorporate CT. For this reason, it is necessary to carefully design new writing tasks to support CT in education. In a recent study, Snodgrass (2011) found that combining a wiki with in-class activities can facilitate collaboration among students to enhance their learning of the complex CT reasoning skill.

In the present research, we tried to adopt different design lines that could support CT development at higher education level. More specifically, collaborative and creative writing were combined with the critical analysis of literature texts and the fruition of figurative arts. These choices were based on the assumption that discourse between peers during a collaborative writing activity could expose them to peers' thinking processes, understanding that there are multiple ways to approach a situation and learning to reconcile different viewpoints and perspectives, which are all central components of CT. In addition, especially in the area of museum education, CT is often associated with Visual Thinking: watching and enjoying a work of art, comparing different artworks, artists, styles, and trends, allows the audience to develop their thinking, analysis and evaluation skills (Housen, 2002).

\section{Module design}

The six month university module here presented is a blended learning course in Educational Research Methodology based at the Department of Education. Students attend classes faceto-face and they also interact on "Formonline", a Moodle platform provided by the University of Roma Tre. During the course, students were invited to use analytical and evaluative skills through the analysis of three short stories written by different authors and based on the works by Edward Hopper ("In Sunlight or in Shadow. Stories inspired by the Paintings of Edward Hopper”, Block L., 2016). At this stage, students worked in classroom collaboratively, comparing their ideas and writing their answers following a template provided by the teacher. Following collaborative creative writing was carried out on a piece of art of their choice. Students used the Moodle wiki tool to write their creative stories. In 
addition, students attended online video lecturing on the "Émile. Ou de l'éducation." written by Rousseau and they were required to write comments on each video and compare their reflection with peers. Students are also required to complete two different kinds of CT pre-test and post-test. At the beginning and at the end of the course they have to write: a) a short essay after reading an excerpt from "The Dialogue Concerning the Two Chief World Systems" written by Galileo Galilei and b) an argumentative map, inspired by the Van Gelder's model (2002).

\section{Data collection and data analysis}

The present research tried to answer the following research questions:

1. Which levels of CT students' groups showed throughout the course?

2. Which kind of group dynamics students reported in relation to the collaborative writing activities?

First year students from the Educational Research Methodology course were involved. 123 students participated in all the activities $(\mathrm{F}=115 ; \mathrm{M}=8$; Average age $=23)$ and they were organized in 17 groups (about 7 students per group). Three different kinds of data were collected.

1. Collaborative analysis of literature texts: in the first three tasks, students answered guiding questions about literary texts assigned by the teacher.

2. Collaborative and creative text: in the fourth task named "Wiki - Narrating the Museum" students created a story based on a piece of art of their choice.

3. Self-reflection questionnaire: at the end of the writing activities, students were invited to answer a questionnaire that investigated the group dynamics and processes;

The following table (Tab. 1) shows the distribution of the writing activities assigned to the students starting from the beginning of the course (Task 1) to the end (Task 4).

Table 1- The distribution of the writing activities from the beginning of the course (Task 1) to the end (Task 4).

\begin{tabular}{cccc}
\hline Task 1 & Task 2 & Task 3 & Task 4 \\
\hline Blue Night & The Music Room & Automat & $\begin{array}{c}\text { Wiki }- \text { Narrating the } \\
\text { museum }\end{array}$ \\
\hline
\end{tabular}

Different kinds of analysis were carried out in order to investigate 1) students' groups CT level and 2) group dynamics (see table 2). Group dynamics were studied by applying a thematic analysis of the qualitative data collected through the online questionnaire. Each 
group of students' CT level was assessed by using two different grids developed in previous research paths (Poce 2011; Poce, Corcione \& Iovine, 2012) on the four collaborative texts: Blue Night, The Music Room, Automat, and Wiki - Narrating the Museum.

The first grid contains five macro-categories: 1. relevance of the topic 2. content 3. form and expression 4. originality and creativity 5. use of the language. For each macro-category a score from 0 to 10 has been assigned. Four independent evaluators read the groups' texts and assigned scores on the five macro-categories. At the end, the average of the four evaluators' scores was calculated.

The second grid contains six macro-categories: 1. basic linguistic skills 2. justification 3 . relevance 4 . importance, 5. critical evaluation 6. novelty. For each macro-category a score from 0 to 5 has been assigned. Two independent evaluators read the groups' texts and assigned scores on the six macro-categories. At the end, the average of the two evaluators' scores was calculated.

Table 2 A description of data collection and data analysis methods

\begin{tabular}{cccc}
\hline Data collection & Data analysis & Purpose of the analysis \\
\hline 1. & $\begin{array}{c}\text { Collaborative analysis of } \\
\text { literature text } \\
\text { 2. Wiki - Collaborative and } \\
\text { creative text }\end{array}$ & Content analysis: & Assess the level of students' \\
& $-\quad$ Grid 1 & \\
\hline Self-reflection questionnaire. & $-\quad$ Grid 2 & \\
& Thematic analysis & $\begin{array}{c}\text { Understanding students' } \\
\text { groups dynamics }\end{array}$ \\
\hline
\end{tabular}

\section{Results}

\section{a) Students' groups CT levels showed throughout the course}

The following image (Figure 1) shows the development of the CT average scores achieved on the four collaborative writing tasks by all the groups. CT average score achieved in the last activity "Wiki - Narrating the museum" is visibly higher $(6,75 / 10)$ than in the three former tasks (about 6,3/10). However, this difference is not statistically significant. 


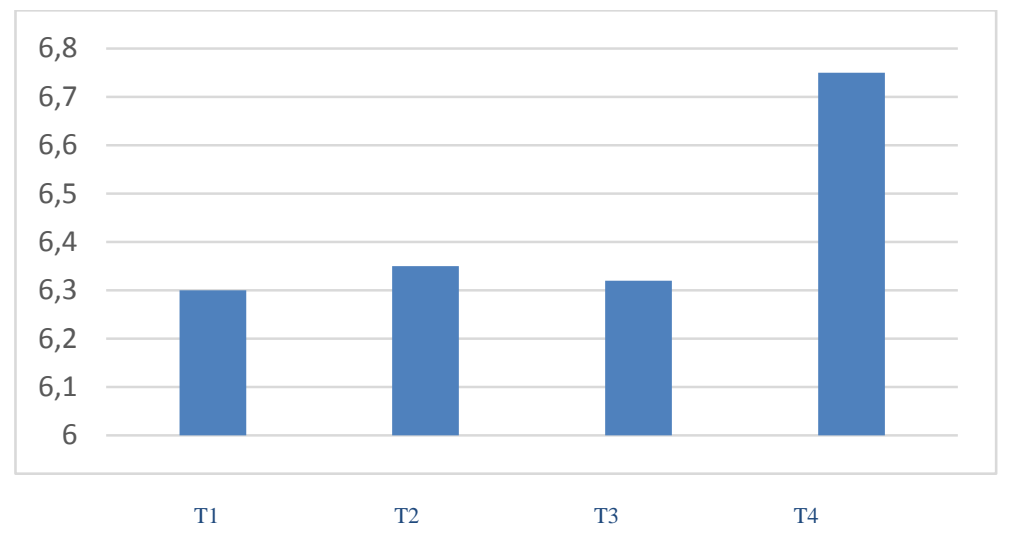

Figure 1 Comparison among the first (Blue night), the second (The Music Room), the third (Automat), and the fourth group (Wiki - Narrating the museum) tasks.

By observing the development for each group, the absence of a common trend throughout the course activity (see as an example the figure 2) can be noticed.

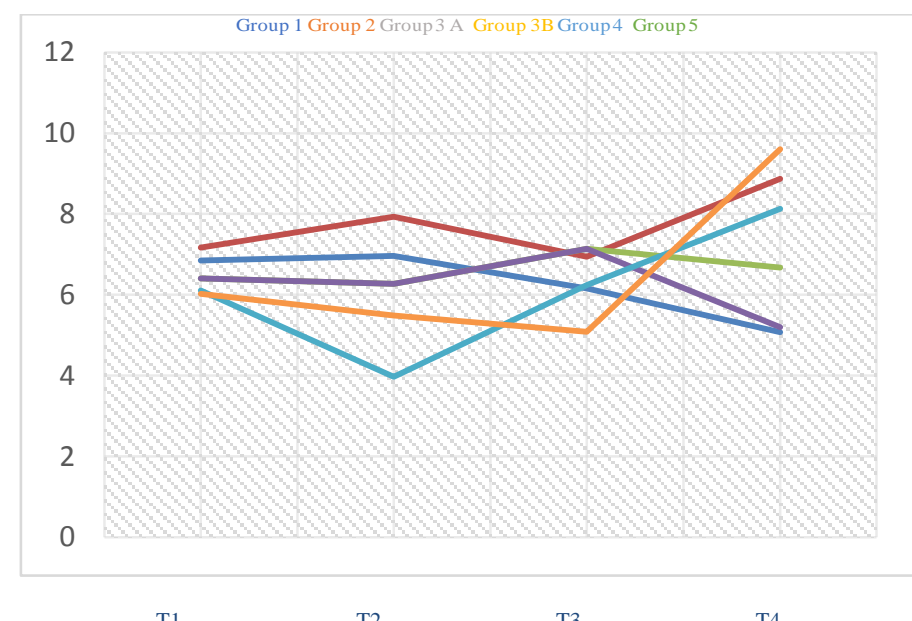

$\mathrm{T} 1$

$\mathrm{T} 2$

$\mathrm{T} 3$

$\mathrm{T} 4$

Figure 2 Group cluster results.

Five trends were identified. Three groups tend to increase their average throughout the module's tasks (e.g. group 2), three groups maintain a steady performance (e.g. 3A), five groups decrease their average scores (e.g. group 1), four groups dip and go up (e.g. group 4) and only two groups seem to improve their average scores and then plunge. 
Table 3 Groups trend throughout the course's tasks

\begin{tabular}{cccccc}
\hline & Increment & Steady trend & Decrement & Go up and dip & Dip and go up \\
\hline Groups & $2,5,16$ & $3 \mathrm{~A}, 6,17$ & $1 ; 12 ; 8 ; 19 ; 15$ & $3 \mathrm{~B}, 14$ & $4,9,11,13$ \\
Total & 3 & 3 & 5 & 2 & 4 \\
\hline
\end{tabular}

It should be noticed that group 3 split into two different groups in the last activity (3A and 3B) and this could explain the different trend of the groups. Despite the different tendencies, seven groups in the final activity showed a higher level of CT comparing to the beginning. Three groups did not vary their performance whilst seven seem to decrease their CT level.

\section{b) Students group dynamics in collaborative writing activities}

It was observed that the groups that showed decrement or steady trends in CT scores, reported also difficulties in managing group dynamics. On the other hand, they also recognised the positive aspects of team working, especially in terms of creativity, like in the following extract (E1):

Extract 1 "Working closely, each of us has been able to see any shortcomings of the other members in different writing fields. Unfortunately, this is one of the disadvantages of not writing individually because you cannot set a medium-high level of writing if not all members are able to support it. I really appreciated the level of our group in the originality field. We worked and collaborated a lot on the plot in order not to make it boring and this is one of the positive aspects of group work because probably by working individually we would not have achieved the same result." (Group 8 - Trend "decrement").

Groups that showed an icrease of their CT level throughout the module, reported a higher awareness of the processes needed to organize cooperative work, such as role taking and the use of different technologies to support collaboration. For instance, group 16 described a clear assignment of roles which included the group coordinator, the curator of the narrative technique, the dialogue, the descriptive technique, the spelling editor, and so on.

Opposite preferences were detected in groups that went up and then dipped comparing to the groups that dipped and eventually went up in terms of CT scores. The formers, indeed, found the tasks realised in the classroom more motivating compared to the wiki activity, that was mainly conducted at distance (E2).

E2 "Certainly the group has been more cohesive and participatory in the class activity, losing the motivation at the time of writing the wiki story. In my opinion, this is due to a rather approximate organization at the time of the roles' division for the writing of the wiki story." Group 14 - Trend "Go up and dip" 
On the contrary, groups that dipped and had a higher score in the last activity were more committed with the creative and collaborative activity of the wiki and some of them reported a strong feeling of ownership, like in the following extract (E3).

E3 "I think that ech of us can be considered a true author of story as a whole because we all discussed together every single word of it. It took us a very long time, but in the end, each of us was satisfied with the result". Group 4 - Trend "Dip and go up"

\section{Discussion and conclusion}

CT development is a pivotal competence to be developed in the higher education system. Rather than be understood just in terms of the individual ability of reasoning, CT is rooted in dialogical and social activities. Through the use of the language, ideas can be explicated and negotiated. For this reason, individual and collaborative writing activities offer opportunities for students to adopt CT in their studies both in synchronous and asynchronous contexts. In the present research, different kinds of collaborative and writing activities were combined to improve students CT.The small dimension of the activity does not allow any generalisation and the results provide an in-depth description of the students' learning and collaborative processes. Groups of students with difficulties in managing their group were not able to improve their CT scores throughout the course. If more skilled in team-working students seemed to increase CT skills. Different trends in CT scores corresponded to different preferences in modalities of collaboration. Some groups preferred the analytical tasks realised in the classroom whilst others preferred the creative work realised with the support of digital technologies. From our perspective, CT is rooted in the ability to work individually and to interact with peers through different kinds of languabe based acts. Collaborative writing tasks need to be carefully designed to support students' CT development, by considering the challenges that students may face. In a further study different kinds of tools could be used. Another aspect which emerged during the study is related to the gender gap which suggests to replicate the activity in different evironments where equal gender presence is represented.

\section{References}

Byrnes, J. P., \& Dunbar, K. N. (2014). The nature and development of critical-analytic thinking. Educational Psychology Review, 26(4), 477-493.

Condon, W., \& Kelly-Riley, D. (2004). Assessing and teaching what we value: The relationship between college-level writing and critical thinking abilities. Assessing Writing, 9(1), 56-75.

Facione, P. (1990). Critical thinking: A statement of expert consensus for purposes of educational assessment and instruction (The Delphi Report). 
Graff, G. (2008). Clueless in academe: How schooling obscures the life of the mind. Yale University Press.

Guiller, J., Durndell, A., \& Ross, A. (2008). Peer interaction and critical thinking: Face-toface or online discussion?. Learning and instruction, 18(2), 187-200.

Housen, A. C. (2002). Aesthetic thought, critical thinking and transfer. Arts and Learning Research, 18(1), 2001-2002.

Kuhn, D., \& Crowell, A. (2011). Dialogic argumentation as a vehicle for developing young adolescents' thinking. Psychological science, 22(4), 545-552.

Murphy, P. K., Rowe, M. L., Ramani, G., \& Silverman, R. (2014). Promoting criticalanalytic thinking in children and adolescents at home and in school. Educational Psychology Review, 26(4), 561-578.

Newman, D. R., Webb, B., \& Cochrane, B. (1995). A content analysis method to measure critical thinking in face-to-face and computer supported group learning. Interpersonal Computing and Technology, 3, 56-77.

Poce, A. (2011). Contribution to the definition of a critical technology. Franco Angeli, Monza.

Poce, A., Corcione, L., \& Iovine, A. (2012). Content analysis and critical thinking. An assessment study. CADMO. 47-63

Quitadamo, I. J., \& Kurtz, M. J. (2007). Learning to improve: using writing to increase critical thinking performance in general education biology. CBE-Life Sciences Education, 6(2), 140-154.

Schindler, L., \& Burkholder Jr, G. J. (2014). Instructional design and facilitation approaches that promote critical thinking in asynchronous online discussions: A review of the literature.

Snodgrass, S. (2011). Wiki activities in blended learning for health professional students: Enhancing critical thinking and clinical reasoning skills. Australasian Journal of Educational Technology, 27(4).

Van Gelder, T. (2002). Argument mapping with reason! able. The American Philosophical Association Newsletter on Philosophy and Computers, 2(1), 85-90. 